\title{
Opioid-induced secondary adrenal insufficiency presenting as hypercalcaemia
}

\author{
Angela S Lee ${ }^{1,2}$ and Stephen M Twigg ${ }^{1,2}$ \\ 'Department of Endocrinology, Royal Prince Alfred Hospital, Camperdown, New South Wales 2050, Australia \\ ${ }^{2}$ Sydney Medical School, Charles Perkins Centre, The University of Sydney, Sydney, New South Wales 2006, Australia
}

\author{
Correspondence \\ should be addressed \\ to S M Twigg \\ Email \\ stephen.twigg@ \\ sydney.edu.au
}

\section{Summary}

Adrenal insufficiency is a rare cause of hypercalcaemia and should be considered when more common causes such as primary hyperparathyroidism and malignancy are excluded. Opioid therapy as a cause of adrenal insufficiency is a possibly under-recognised endocrinopathy with potentially life-threatening adverse effects. We report on a case of opioid-induced secondary adrenal insufficiency presenting as hypercalcaemia. The patient was a 25 -year-old man who developed hypercalcaemia during the recovery stage after a period of critical illness. Systematic investigation of his hypercalcaemia found it to be due to secondary adrenal insufficiency, developing as a consequence of methadone opioid analgesia. Treatment with i.v. saline and subsequent glucocorticoid replacement led to resolution of the hypercalcaemia.

The hypoadrenalism resolved when opioids were subsequently weaned and ceased. These two interacting endocrinopathies of opioid-induced adrenal insufficiency and consequent hypercalcaemia highlight the importance of maintaining awareness of the potentially serious adverse clinical outcomes which can occur as a result of opioids, particularly considering that symptoms of hypoadrenalism can overlap with those of concomitant illness. Treatment with hydration and glucocorticoid replacement is effective in promptly resolving the hypercalcaemia due to hypoadrenalism. Hypoadrenalism due to prescribed and recreational opioids may be more common than is currently recognised.

\section{Learning points:}

- Opioid therapy can cause clinically significant secondary adrenal insufficiency, and this may be more common than is currently recognised.

- Adrenal insufficiency is reversible after discontinuation of the opioid therapy.

- Hypercalcaemia can occur as a consequence of adrenal insufficiency, and may be the presenting feature.

- Treatment of hypercalcaemia due to adrenal insufficiency involves i.v. saline and glucocorticoid replacement.

\section{Background}

Opioids are commonly used for the treatment of acute and chronic pain. Clinicians need to be aware of the potential side-effects of opioids on the endocrine system. While opioids are a well-recognised cause of hypogonadotropic hypogonadism (1), significant effects on the hypothalamic-pituitary-adrenal (HPA) axis can also occur with both acute and chronic opioid usage (2) (3), with potentially serious adverse clinical outcomes if left untreated. Recovery of the HPA axis can occur with discontinuation of the opioid therapy. Adrenal insufficiency is a rare but important cause of hypercalcaemia (4). We report a case of hypercalcaemia subsequently shown to be due to opioid-induced secondary adrenal insufficiency, with the resolution of hypercalcaemia occurring after i.v. saline infusion and glucocorticoid replacement.

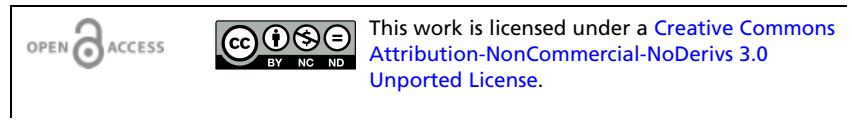




\section{Case presentation}

A 25-year-old Caucasian man was found to have hypercalcaemia on blood results performed whilst undergoing inpatient rehabilitation. Six weeks prior, he presented after a multiple drug overdose and was treated in the intensive care unit (ICU) for pneumonia, rhabdomyolysis, acute kidney injury, and neuropathic pain. During the initial week of ICU admission, a transient moderate hypercalcaemia (Fig. 1) was considered to be multifactorial in aetiology involving rhabdomyolysis, artificial feeding, and immobility. This hypercalcaemia resolved within the 1st week of admission, and 6 weeks of normocalcaemia followed.

He was then transferred to a local rehabilitation hospital and was found to have severe hypercalcaemia with a serum corrected calcium peak of $3.16 \mathrm{mmol} / \mathrm{l}$ (RR 2.10-2.60 mmol/l) (Fig. 1). At this stage he was consuming a regular diet and ambulating $50 \mathrm{~m}$ daily using a walking frame, and his renal function had been normal for the previous 4 weeks. There were no overt clinical signs of adrenal insufficiency. His medications included duloxetine, quetiapine, pregabalin, and methadone $20 \mathrm{mg}$ in the morning and $15 \mathrm{mg}$ in the evening for pain relief. Prior to the hospital admission he had not been taking any regular opioids, but had intermittently abused illicit drugs including heroin.

\section{Investigation}

Initial investigations showed a low serum parathyroid hormone (PTH) level of $0.6 \mathrm{pmol} / \mathrm{l}$ (RR 2.0-6.0 pmol/l) (Table 1). Malignancy-induced hypercalcaemia was considered unlikely given that he had no history of malignancy, no tumours on CT imaging of the chest,

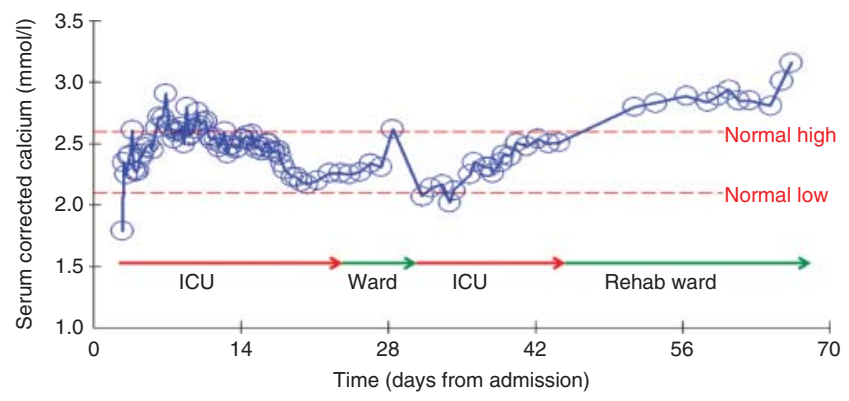

Figure 1

Serum corrected calcium with time showing the initial 1 week of moderate hypercalcaemia during the patient's intensive care unit admission, followed by 6 weeks of normocalcaemia, and then subsequent severe hypercalcaemia. abdomen and pelvis, and an undetectable PTH-related peptide level. He had no clinical or radiological evidence on CT or gallium scan of sarcoidosis or lymphadenopathy. Also, his $1,25(\mathrm{OH})_{2}$ Vitamin D level was not elevated, making sarcoidosis and other granulomatous conditions unlikely to be the underlying cause of hypercalcaemia. Further assessment of this PTH-independent hypercalcaemia effectively excluded the differential diagnoses of hyperthyroidism, Vitamin D intoxication, Vitamin A intoxication, rhabdomyolysis, milk-alkali syndrome, immobility and acromegaly. His morning serum cortisol was found to be markedly low at $46 \mathrm{nmol} / \mathrm{l}$ (RR 200$600 \mathrm{nmol} / \mathrm{l}$ ) in the context of a normal sleep-wake cycle. His hospital file was carefully reviewed and he was confirmed to have not received any exogenous glucocorticoids during his hospital admission, including during the period of critical illness in the ICU. There were no previous cortisol results for comparison, as there had been no clinical need for testing earlier in his admission. The hypocortisolaemia was promptly further investigated.

His pituitary profile was consistent with secondary adrenal insufficiency: ACTH $<1.1 \mathrm{pmol} / \mathrm{l}$ (RR $<10 \mathrm{pmol} / \mathrm{l})$, with a repeated morning serum cortisol $159 \mathrm{nmol} / \mathrm{l}$ (RR 200-600 nmol/l). The pituitary-gonadal axis was preserved: LH $5.9 \mathrm{IU} / 1$ (RR 1.7-8.6 IU/l), FSH $4.4 \mathrm{IU} / 1$ (RR 1.0-9.0 IU/l), morning testosterone $27.9 \mathrm{nmol} / \mathrm{l}$ (RR $6.0-29.0 \mathrm{nmol} / \mathrm{l})$. Prolactin was mildly elevated at $33 \mathrm{ng} / \mathrm{ml}$ (RR 2.0-16.0 ng/ml), which was thought to be likely due to the duloxetine. IGF1 was mildly elevated in this rehabilitation phase at $48.5 \mathrm{nmol} / \mathrm{l}$ (RR $11.6-37.1 \mathrm{nmol} / \mathrm{l})$, with normal GH $1.1 \mathrm{ng} / \mathrm{ml}(\mathrm{RR}<6.0 \mathrm{ng} / \mathrm{ml})$. Thyroid function profile revealed TSH $0.83 \mathrm{mIU} / \mathrm{l}$ (RR $0.27-4.20 \mathrm{mIU} / \mathrm{l}$ ) and a mildly low free thyroxine $\left(\mathrm{T}_{4}\right) 10.7 \mathrm{pmol} / \mathrm{l}$ (RR $12.0-25.0 \mathrm{pmol} / \mathrm{l})$, likely representing a sick euthyroid syndrome in the setting of nonthyroidal illness.

The cause of his secondary adrenal insufficiency was considered to be the methadone opioid analgesia commenced in the 6th week of his hospital admission, then maintained owing to neuropathic pain. He had not exhibited clinical signs of adrenal insufficiency during the course of his preceding ICU admission, and he had not received any previous glucocorticoid. The subsequent development of hypercalcaemia in the 6th week of his hospital admission was the presenting feature of his adrenal insufficiency.

\section{Treatment}

I.v. saline infusion was commenced, which resulted in near-normalisation of serum calcium over 3 days (Fig. 2). 
Table 1 Investigations for PTH-independent hypercalcaemia.

\begin{tabular}{|c|}
\hline Investigation \\
\hline $\begin{array}{l}\text { Blood tests } \\
\text { Serum calcium (uncorrected) (mmol/l) } \\
\text { Serum albumin }(\mathrm{g} / \mathrm{l}) \\
\text { Serum corrected calcium }(\mathrm{mmol} / \mathrm{l}) \\
\text { Serum ionised calcium }(\mathrm{mmol} / \mathrm{l}) \\
\text { Serum magnesium }(\mathrm{mmol} / \mathrm{l}) \\
\text { Serum phosphate }(\mathrm{mmol} / \mathrm{l}) \\
\text { Serum bicarbonate }(\mathrm{mmol} / \mathrm{l}) \\
\text { Serum parathyroid hormone }(\mathrm{pmol} / \mathrm{l}) \\
\text { Serum creatinine }(\mu \mathrm{mol} / \mathrm{l}) \\
25-\mathrm{OH} \text { Vitamin D }(\mathrm{nmol} / \mathrm{l}) \\
1,25(\mathrm{OH})_{2} \text { Vitamin D } \\
\text { TSH (mIU/l) } \\
\text { Free } \mathrm{T}_{4}(\mathrm{pmol} / \mathrm{l}) \\
\text { Morning serum cortisol (nmol/l) } \\
\text { IGF1 (nmol/l) } \\
\text { PTH-related peptide (pmol/l) } \\
\text { Creatinine kinase }(\mathrm{U} / \mathrm{l}) \\
\text { Vitamin A ( } \mu \text { mol/l) } \\
\text { Myeloma screen (EPG/IEPG) }\end{array}$ \\
\hline $\begin{array}{l}\text { Urine tests } \\
24 \mathrm{~h} \text { urine calcium (mmol/day) } \\
\text { Urine deoxypyridinoline (DPD):creatinine } \\
\text { (nmol/mmol cr) } \\
\text { Imaging } \\
\text { CT chest/abdomen/pelvis }\end{array}$ \\
\hline Gallium scan \\
\hline
\end{tabular}

Patient result (abnormal levels in bold)
2.77
37
2.89 (peak $3.16 \mathrm{mmol} / \mathrm{l}$ in admission)
1.46
$\mathbf{0 . 6 0}$
2.15
31
0.6
44
44
49 nmol/l
0.83
10.7
46
48.5
$<2.0$
59
1.5
No paraprotein detected. No monoclonal
$\quad$ immunoglobulins
11.9
46.8
No tumours. No signs of sarcoidosis.
Normal adrenal glands.
No abnormal pathology

Reference range

$2.10-2.60$

$38-48$

$2.10-2.60$

$1.15-1.29$

$0.70-0.95$

$0.85-1.50$

$24-32$

$2.0-6.0$

$70-110$

$>60$

$60-158 \mathrm{pmol} / \mathrm{l}$

$0.27-4.20$

$12.0-25.0$

$200-600$

$11.6-37.1$

$<2.0$

$0-250$

$1.4-4.0$

No abnormal pathology

He was then commenced on $20 \mathrm{mg}$ twice daily of oral hydrocortisone which normalised the serum calcium. Within 1-2 h of hydrocortisone initiation, he reported that he felt clinically improved, with resolution of lethargy.

Ten days after the initial commencement of hydrocortisone, the hydrocortisone was then withheld for $24 \mathrm{~h}$ prior to a $250 \mu \mathrm{g}$ short synacthen test. The subnormal cortisol response to synacthen confirmed the diagnosis of adrenal insufficiency (serum cortisol 26, 343, $426 \mathrm{nmol} / \mathrm{l}$ at 0, 30, 60 min respectively). The serum calcium became elevated again after the hydrocortisone therapy was temporarily withheld for the dynamic testing, and then normalised on hydrocortisone re-initiation (Fig. 2) confirming the necessity of ongoing glucocorticoid in the treatment of hypercalcaemia. A pituitary MRI found no anatomical lesion to explain the secondary adrenal insufficiency.

He was continued on oral hydrocortisone $20 \mathrm{mg}$ morning and $10 \mathrm{mg}$ afternoon for secondary adrenal insufficiency, and remained well across subsequent months, without recurrence of hypercalcaemia.

\section{Outcome and follow-up}

The methadone opioid analgesia was weaned after 5 months. Three months after cessation of the opioid, he had complete recovery of his HPA axis as shown by a morning serum cortisol $617 \mathrm{nmol} / \mathrm{l}$, and ACTH $19 \mathrm{ng} / \mathrm{l}$ (RR 10-60 ng/l) each after more than $24 \mathrm{~h}$ hydrocortisone cessation. He remained normocalcaemic, confirming that

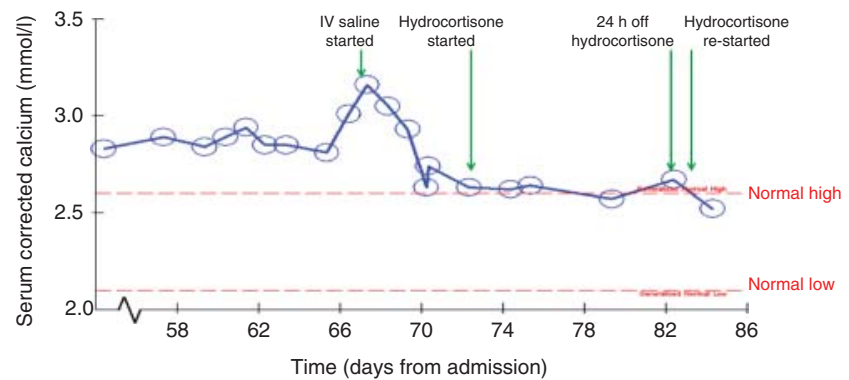

Figure 2

Resolution of hypercalcaemia after treatment with i.v. saline and oral hydrocortisone. 
the opioid-induced hypoadrenalism and consequent hypercalcaemia was a reversible phenomenon.

\section{Discussion}

Opioids are commonly used for the treatment of pain, and their effects on the HPA axis may be under-recognised (1) (2) (3). Adrenal insufficiency is an uncommon cause of hypercalcaemia (4) (5). The time-course of documented opioid use in this case is consistent with methadone causing the secondary adrenal insufficiency and consequent hypercalcaemia. The resolution of hypercalcaemia through initial hydration and then ongoing glucocorticoid replacement, further supports this diagnosis. Finally, the recovery of the HPA axis after cessation of opioid, and the subsequent persistence of normocalcaemia off hydrocortisone replacement confirms the opioid linked and reversible nature of his disease.

This case of opioid-induced secondary adrenal insufficiency presenting as hypercalcaemia exemplifies two interacting endocrinopathies. Firstly, hypercalcaemia can occur in both primary and secondary adrenal insufficiency (4) (5). One case series found a $6 \%$ prevalence of hypercalcaemia at the time of diagnosis of Addison's disease (4). The postulated mechanism of adrenal insufficiency causing hypercalcaemia is through a combination of increased calcium flux into the extracellular space and reduced calcium renal excretion (6). Decreased glomerular filtration results in a reduced filtered load of calcium, and increased calcium renal reabsorption occurs due to volume depletion in adrenal insufficiency. Enhanced calcium mobilisation from bone by hypoadrenalism also contributes to the development of hypercalcaemia (6) (7). The elevated phosphate level in our patient, which normalised with hydration and glucocorticoid, has also been reported to be associated with hypoadrenalism (5) (6).

Secondly, opioids may cause secondary adrenal insufficiency, which a recent report suggests is underrecognised (3). Acute administration of oral morphine can cause significant suppression of serum basal cortisol and plasma ACTH (8). In chronic methadone-addicted patients, a significantly blunted cortisol release after 1-24 $\alpha$ adrenocorticotrophin administration has been demonstrated in group data (9). In another series, an inadequate peak cortisol response to insulin-induced hypoglycaemia was reported in $15 \%$ of patients treated with long-term intrathecal opioids (10). In the same study, the majority, but not all, patients developed hypogonadotropic hypogonadism. It is interesting that our patient's pituitary-gonadal axis was preserved; the selective effect on the HPA axis may be explained by the different opioid receptor subtypes involved: $\delta$ - and $\kappa$ - receptors for ACTH, and $\varepsilon$ - receptors for LH (1). ACTH secretion is under tonic inhibition by endogenous opioids at hypothalamic and/or pituitary levels, and administration of exogenous opioids may thus cause suppression of plasma ACTH and serum cortisol, particularly in a subgroup of susceptible individuals (1) (8). At present, there are no predictive tests to pre-identify which people are at high risk of developing hypoadrenalism following opioid exposure.

To our knowledge, this is the first case of opioidinduced adrenal insufficiency presenting as hypercalcaemia. Opioid-induced secondary adrenal insufficiency may be more common than is recognised and can have serious adverse clinical outcomes if it is not detected and managed. Currently, there are no guidelines for the screening of patients on opioids for possible secondary hypoadrenalism, and an awareness of this endocrinopathy is essential to guide appropriate treatment with glucocorticoid replacement, particularly considering that symptoms of adrenal insufficiency can overlap with those of concomitant illness.

\section{Declaration of interest}

The authors declare that there is no conflict of interest that could be perceived as prejudicing the impartiality of the research reported.

\section{Funding}

This research did not receive any specific grant from any funding agency in the public, commercial or not-for-profit sector.

\section{Patient consent}

The authors confirm that written informed consent was obtained from the patient for publication of the submitted article through his signature on their consent form.

Author contribution statement

Dr A Lee attended on the patient and drafted the manuscript; Prof. S Twigg supervised the care of the patient and was involved in critical revision of the manuscript.

\section{References}

1 Grossman A, Moult PJ, Cunnah D \& Besser M 1986 Different opioid mechanisms are involved in the modulation of ACTH and gonadotrophin release in man. Neuroendocrinology 42 357-360. (doi:10.1159/ 000124463) 
2 Policola C, Stokes V, Karavitaki N \& Grossman A 2014 Adrenal insufficiency in acute oral opiate therapy. Endocrinology, Diabetes \& Metabolism Case Reports 2014 130071. (doi:10.1530/EDM-13-0071)

3 Singh N, Snyder RW \& Krishnamurthy M 2014 An under-recognized and under-reported cause of adrenal insufficiency. International Journal of Case Reports in Medicine 2014 (Article ID 524908). (doi:10.5171/2014.524907)

4 Nerup J 1974 Addison's disease - clinical studies. A report of 108 cases. Acta Endocrinologica 76 127-141. (doi:10.1530/acta.0.0760127)

5 Wong RK, Gregory R \& Lo TC 2000 A case of isolated ACTH deficiency presenting with hypercalcaemia. International Journal of Clinical Practice 54 623-624.

6 Muls E, Bouillon R, Boelaert J, Lamberigts G, Van Imschoot S, Daneels R \& De Moor P 1982 Etiology of hypercalcemia in a patient with Addison's disease. Calcified Tissue International 34 523-526. (doi:10.1007/BF02411297)
7 Willems D, Gillet C, Cogan E, Fuss M \& Bergmann P 1991 Biological parameters of bone remodelling in chronic adrenal insufficiency. Hormone and Metabolic Research 23 511-512. (doi:10.1055/s-20071003742)

8 Allolio B, Schulte HM, Deuss U, Kallabis D, Hamel E \& Winkelman W 1987 Effect of oral morphine and naloxone on pituitary-adrenal response in man induced by human corticotropin-releasing hormone. Acta Endocrinologica 114 509-514. (doi:10.1530/acta.0.1140509)

9 Dackis CA, Gurpegui M, Pottash AL \& Gold MS 1982 Methadone induced hypoadrenalism. Lancet 2 1167. (doi:10.1016/S0140-6736 (82)92830-6)

10 Abs R, Verhelst J, Maeyaert J, Van Buyten JP, Opsomer F, Adriaensen H, Verlooy J, Van Havenbergh T, Smet M \& Van Acker K 2000 Endocrine consequences of long-term intrathecal administration of opioids. Journal of Clinical Endocrinology and Metabolism 85 2215-2222. (doi:10.1210/jcem.85.6.6615)

Received in final form 6 June 2015

Accepted 18 June 2015 